\title{
Arte, pesquisa e universidade
}

\author{
Raimundo Martins
}

\section{Resumo}

Este artigo analisa paradigmas e paradoxos do conhecimento e da arte pondo em perspectiva conflitos epistemológicos e contradições que delinearam uma trajetória histórica e estética, gerando oscilações e alternâncias acerca das concepções de mente e corpo como 'locus' de percepção, conhecimento e expressão. Examina as relações de descontinuidade e fragmentação entre graduação e pós-graduação, enfatizando a pesquisa como vital à uma formação que integre temas/questões empíricos, teóricos, práticos e metodológicos. Propõe uma epistemologia da arte que contemple modalidades de conhecimento 'não-proposicional' e 'proposicional', abrangendo diferentes formas de experiência e aprendizado cultural e artístico.

Palavras-chave: arte, pesquisa, universidade, pós-graduação, graduação.

\section{Abstract}

This article analyzes paradigms and paradoxes of knowledge and art putting in perspective epistemological conflicts and contradictions that delineated a historical and aesthetical trajectory creating oscillations and alternations about the conceptions of mind and body as "locus" of perception, knowledge and expression. It examines relations of discontinuity and fragmentation between graduate and undergraduate studies emphasizing research as vital for a professional training that integrates empirical, theoretical, practical and methodological themes and questions. It proposes an art epistemology which takes into account "non propositional" and "propositional" knowledge, including different forms of cultural and artistic experience and learning.

Key words: art, research, university, graduate, undergraduate studies. 
Ao aceitar o convite para proferir a Aula Inaugural do Programa de Pós-Graduação em Artes Visuais da Universidade Federal da Paraíba, fui surpreendido ao experimentar uma sensação estranha: pensava em temas que me defrontam com idéias ambíguas, temas que atraem ao mesmo tempo em que intrigam e rechaçam minha curiosidade. Buscando definir, e, sobretudo, encontrar uma maneira para abordar o que seria um tema para essa aula inaugural, me flagrei diversas vezes em litígio com as idéias de arte, pesquisa, graduação e pós-graduação.

Embora familiares essas ideias evocam ambiguidades que se distendem em vários campos. O modo de abordá-las pode ampliar, alterar ou até mesmo estreitar nossas concepções reportando-nos a passados distantes, emudecidos pelo tempo. Pode, também, nos ajudar a examiná-las a partir de uma perspectiva crítica, revendo interpretações ameaçadas por preconceitos ou por visões ortodoxas que teimam em nos sitiar nessa discutível pós-modernidade.

Ao esboçar essas idéias e pontos de vista, pretendo partilhar algumas reflexões na expectativa de que elas possam nos ajudar a discutir e rever criticamente alguns conceitos/concepções sobre arte, pesquisa, graduação e pós-graduação. É necessário estar atentos para o fato de que a cena cultural e artística e as condições de sua produção e recepção mudaram rapidamente nas duas últimas décadas transformando os fios de significado que dão forma aos nossos conceitos e concepções. Ao mesmo tempo, também é necessário manter em perspectiva o fato de que o modo como cada um de nós vê, pensa e compreende essas idéias, depende das nossas histórias individuais e do modo como construímos nossas subjetividades.

\section{Paradigmas e paradoxos do conhecimento e da arte}

Vivemos um momento de contradição e mudanças, mais acelerado e complexo que outros períodos que nos antecederam. As mudanças, que às vezes dão a impressão de ser a contingência de um momento, parecem se prolongar indefinidamente. Para alguns indivíduos, as mudanças geram inquietação; para outros, perplexidade. Há também aquelas pessoas que, na expectativa genuína, mas, talvez, ingênua, de encontrar mecanismos de autoproteção, assumem atitude de resignação, sucumbindo à conveniência da apatia ou até mesmo da negligência diante de tais mudanças.

Preceitos e referências antes considerados estáveis se dissolvem como elementos solúveis no rescaldo de uma revolução cultural e tecnológica sem precedentes. Estamos testemunhando o enfraquecimento de tradições políticas e intelectuais num cenário global que, surpreendentemente, se abre às diferenças culturais, étnicas e de gênero. 
Se examinarmos cuidadosamente a história das instituições acadêmicas, suas trajetórias e os modos como sua história é representada, vamos constatar que a idéia de conhecimento e a construção desse aparato conceitual que conhecemos como "teoria", foi escrita e descrita como uma evolução linear, contínua, desde os tempos antigos. A função principal de uma teoria é explicitar o modo como idéias, fenômenos, vivências, habilidades e práticas são organizados através de exercícios graduais e constantes, constituindo um corpus de conhecimento que pode ser identificado e reconhecido pelos conceitos e métodos com os quais é transmitido e/ou aprendido.

No Ocidente, as teorias estão fundamentadas em concepções, práticas e modelos de organização que privilegiam as formas de conhecimento "proposicional". Essas formas se estruturam a partir de um princípio de ordenação lógico-linear que favorece as modalidades de conhecimento cujos conteúdos e métodos podem ser transmitidos e aprendidos pela mediação de códigos, fórmulas e discursos verbais. Essa linearidade lógica é aplicável a discursos que não levam em consideração o imenso repertório e fluxo de criações e informações visuais a que estamos expostos diariamente.

Na cultura ocidental essa ênfase no verbal privilegiou certas modalidades de conhecimento em detrimento de outras. Gerou práticas e traçou uma trajetória epistemológica na qual a relação mente/corpo se configurou como paradigma que hierarquiza e subordina outras áreas de conhecimento decorrentes dessa relação.

Essa hierarquia está evidente na nomenclatura que adotamos para a pesquisa assim como em seus procedimentos e práticas. O jargão metodológico que usamos, resultado de uma tradição de séculos, incorpora e sintetiza contradições epistemológicas e preconceitos históricos que através de pares semânticos, veiculam conhecidas dicotomias como teoria-prática, pensar-fazer, eidético-empírico, objetivo-subjetivo, e assim por diante.

As escolas de pensamento - idealismo, realismo, existencialismo, empiricismo e pragmatismo - através de reflexões, especulações e discussões filosóficas, estabeleceram concepções sobre "a realidade", o funcionamento da mente e do corpo, criando paradigmas do conhecimento, suas modalidades e funções. As práticas que hoje conhecemos como ciência e como arte têm suas raízes nessas concepções.

As modalidades de conhecimento não proposicional, mais especificamente as artes, realizaram uma trajetória histórica e estética que registra oscilações e alternâncias entre mente e corpo como 'locus' de percepção, conhecimento e expressão. As condições e situações que marcam essa trajetória são, também, registros de como a teorização sobre a produção artística dependeu ora de favores, ora de concessões dos paradigmas vigentes (proposicionais) de conhecimento. Ainda hoje, certos estereótipos são mantidos 
e reforçados pelo senso comum atestando, inclusive, por pesquisadores de várias áreas, a pouca credibilidade da arte como campo de conhecimento.

\section{Um conflito epistemológico}

De acordo com a premissa cartesiana, seres humanos são ao mesmo tempo corpo e mente. O corpo que se move, que fala, canta, desenha, pinta, que opera de maneira visível, exposto a observação externa, concreta e objetiva. A mente que pensa, imagina, registra e organiza informações, códigos e imagens, monitora processos abstratos, subjetivos, não observáveis.

Essa dicotomia entre corpo e mente dá origem a dois tipos de existência. A primeira, uma existência física centrada no corpo, que materializa uma existência biológica e tem seus limites em referências de tempo e espaço. A segunda, uma existência centrada na mente, fecundada por idéias, sentimentos e intenções que se organizam numa rede de significados simbólicos. O corpo, que nasce, cresce, envelhece e morre esculpindo marcas e trajetórias no tempo. A mente, uma invenção/construção que emerge no contexto de uma cultura inscrevendo suas participações em espaços individuais e coletivos. Cada uma dessas existências, física e mental, se constrói através de ações, vivências, experiências e aprendizagens cuja historicidade dependerá do que vier a acontecer no corpo e com o corpo, na mente e com a mente.

Assim, o mesmo indivíduo passa a habitar dois mundos que correspondem a dois tipos de existência e de conhecimento. A existência física - externa, observável que pode gerar conhecimento concreto e objetivo. A existência mental - interna, não observável - que pode gerar conhecimento abstrato e subjetivo.

Essa dicotomia corpo/mente intensificou gradativamente o conflito entre a existência física e a existência mental propiciando o surgimento de concepções e procedimentos que, aos poucos, diferenciaram e sedimentaram visões e práticas específicas: fazer e pensar. Essas visões foram exacerbadas ao extremo, a ponto de protagonizar a crença de que fazer e pensar ou, existência física e existência mental, são incompatíveis.

A crença nessa incompatibilidade advém da dificuldade de compreender e explicar como percepções, dados, experiências e fatos do mundo físico podem ser transmitidos ao mundo da mente e vice-versa. Como fenômenos e estímulos do mundo físico podem gerar respostas em uma mente oculta no seu silêncio ou, ainda, como uma atitude construída na mente pode se transformar em ação que põe o corpo em movimento. Em outras palavras, "o que a mente deseja, pernas, braços e língua executam; porque as coisas que atraem os olhos e os ouvidos têm relação com o que a mente percebe?" (RYLE, 1963, p. 14). 
Esse modo dualista de ver e fazer mundos transformou-se em paradigma para a ciência e em enigma para a arte, duas versões de mundo construídas através de sistemas simbólicos. Essas versões de mundo revelam um conflito de concepções, ou seja, construções simbólicas que são consideradas legítimas quando estudadas separadamente, mas incompatíveis entre si quando confrontadas. Dizendo de outra maneira, "o que consideramos mundo e o que consideramos discurso sobre o mundo depende das nossas convenções..., pode ser produto de hábito ou de consentimento comum" (GOODMAN, 1995, p.8).

O dualismo mente/corpo, com suas versões e argumentos, fundamentou as concepções de conhecimento do mundo ocidental, criando uma espécie de cartografia lógica, definindo percursos e procedimentos metodológicos que até hoje influenciam o nosso modo de pensar e fazer. Como paradigma dominante, esse dualismo deveria orientar a nossa busca de compreensão sobre conhecimento em arte. No entanto, a prática que se impõe ou que temos como referência, tem base numa versão de mundo recheada de contradições e suposições empíricas que se alternam com descrições de caráter introspectivo, pouco consistentes ou rigorosas.

A dicotomia corpo/mente caracterizou os mecanismos e operações da mente como processos autênticos, e, por esta razão, superiores. O acesso aos processos e operações da mente, é um privilégio que só a mente tem. Essa condição dá à mente um caráter de privacidade e autonomia que o corpo não possui. A capacidade de operar de maneira silenciosa, secreta, processando noções de tempo e espaço, abstraindo e criando formas, cores, volume e imagens, deu às atividades da mente uma credibilidade que a colocou em posição de superioridade e domínio em relação ao corpo. Essa relação hierárquica da mente sobre o corpo levou filósofos e leigos a tratar as operações do intelecto como as operações principais. Atribuiu-se à mente a capacidade exclusiva de realizar operações confiáveis para processar informações, estímulos, eventos e fatos do mundo da existência física e do mundo da existência mental. As operações abstratas tornaram-se o exercício cognitivo por excelência e passaram a ser associadas a uma classe especial de operações que sintetiza essa superioridade: a teoria.

A importância da teoria advém do fato de ser uma operação mental que pode ser conduzida em silêncio, de maneira autônoma, com o propósito de desvendar ou gerar conhecimento sobre idéias, fenômenos e fatos. Dessa maneira se estabeleceu a compreensão de que o caminho de acesso ao conhecimento tem nas operações da mente uma via de mão única, atribuindo à capacidade de "teorizar a superioridade de homens sobre animais, de civilizados sobre bárbaros, da mente divina sobre as mentes humanas" (RYLE, 1963, p. 27). Qualquer outra modalidade de conhecimento teria que ser demonstrada através de formulações intelectuais para ser validada e aceita. A supremacia da teoria estabeleceu o intelecto como parâmetro do conhecimento e a razão como referência para o que poderia ser considerado "verdade". 
A contradição teoria/prática incorpora uma dicotomia que, como outras, é oscilante. Isso porque, uma contradição, não necessariamente elimina a dinamicidade existente entre os conceitos que ela envolve. Essa dinamicidade que faz com que os conceitos de uma contradição possam oscilar, ora permitem uma análise que enfatiza maneiras de explicar e compreender pedaços da realidade, ora nos reúne em torno de fragmentos que permitem agir, até com certa sistematicidade, a partir de, ou, dentro e sobre certas condições de realidades.

Se eliminarmos essa possibilidade de oscilação, ou seja, uma certa dinamicidade entre conceitos aparentemente contraditórios ou dicotômicos, atrofiamos ou hipertrofiamos o significado desses conceitos. Nesse sentido, teoria e prática se tornam não apenas dicotômicos, mas antagônicos. Esta visão antagônica está profundamente enraizada em nossa cultura, nas concepções sobre o conhecimento artístico e outros tipos de conhecimento qualitativo. Não faz sentido falar de realidade sem considerar uma versão de mundo que a contextualize, da mesma maneira que "comparar uma teoria com uma experiência é comparar uma versão com outra versão” (GOODMAN, 1995, p.7). Nossa visão antagônica sobre teoria e prática está construída a partir desta falsa premissa, ou seja: comparar versões de mundo.

O corpus de conhecimento de uma área é constituído a partir de práticas e conceitos que se consolidam através do tempo. O conteúdo epistemológico de uma área, nesse caso, a área de arte, é uma espécie de declaração de problemas, paradigmas e teorias, registrando e organizando as atividades dos seres humanos nas suas tentativas de construir respostas, alternativas e soluções para as questões que a área enuncia. Nasce do interesse ou necessidade de explorar de maneira metódica e sistemática determinados tipos de fenômenos, idéias ou relações, o modo como estão organizados, como se desenvolvem, as explicações e produtos que geram.

Assim, o conteúdo epistemológico da arte inclui um sistema de juízos de valor que é construído paralelamente ao desenvolvimento de técnicas, métodos, formas e estilos. Tais juízos de valor podem estar arraigados a práticas antiquadas, desprovidas de crítica e envelhecidas pela ação anestesiante da repetição, gerando distorções ou resultados que comprometem a área. Outra função da epistemologia da arte é explicar, através da investigação e da crítica, os equívocos, as distorções e os desvios, sintonizando as teorias com as práticas e as práticas às especulações da teoria. Prática e teoria são, nesta função, objetos de investigação e crítica. Da relação prática/teoria, com suas implicações e contradições, nasce uma configuração de referentes e significados explícitos e implícitos, verbais e não verbais que constituem a modalidade de conhecimento que identificamos como arte. 


\section{Graduação e Pós-Graduação: monólogos ou diálogos?}

A função precípua da universidade pode ser sintetizada em dois pólos: preservar e gerar conhecimento. A concretização dessa função dá-se através de um processo de formação e qualificação de recursos humanos. A preservação de conhecimento, tarefa geralmente atribuída aos cursos de graduação, tem sua ênfase na formação de profissionais que atuam na sociedade lidando com modalidades e práticas de um saber adquirido na instituição. Por sua vez, a geração de conhecimento, é vista como prerrogativa quase que exclusiva dos programas de pós-graduação que têm como meta formar docentes/ pesquisadores. Essa associação dos cursos de graduação à idéia de preservação, e dos programas de pós-graduação à geração de conhecimento, se mantém como tradição na universidade brasileira.

Fiel à sua origem e antecedentes históricos, o ensino de graduação é caracterizado por uma visão conservadora, concepção que tem como foco a aprendizagem como um ato de contemplação do passado. Historicamente, a expressão máxima dessa concepção/ modelo teve a figura do catedrático como símbolo e fonte de conhecimento. Inspirada em resquícios de um modelo formal da cultura clássica que, de certa forma, negava e manipulava a dimensão política e cultural do conhecimento, a cátedra se notabilizou como um instrumento de controle intelectual. $\mathrm{O}$ conhecimento oriundo da cátedra tinha um caráter prescritivo. Era transmitido com o objetivo de conservar conceitos e práticas fundamentados, quase que exclusivamente, na tradição e no princípio da autoridade. Todavia, a diversificação e ampliação das áreas de conhecimento associada à necessidade de especialização criadas pelo avanço da pesquisa, pelo mercado de trabalho e, especialmente, pela revolução tecnológica, aceleraram a deterioração desse modelo tornando-o obsoleto. A figura do catedrático, símbolo da hierarquia e autoridade acadêmica, foi abolida, mas o seu espírito arraigado à tradição e à autoridade do professor continua presente na universidade. Lamentavelmente, ainda há colegas professores que se apresentam como fonte inquestionável de conhecimento. Esse espírito é ineficiente para gerar competência e criticidade na formação profissional.

A diversificação, os diferentes graus de especialização e a aceleração tecnológica são retratos da crescente fragmentação e transformação do conhecimento. Na universidade, essa fragmentação ocorre de maneira peculiar, emprestando sofisticação e requinte ao ensino de pós-graduação. As especificidades se materializam em forma de áreas de concentração, ênfases e linhas de pesquisa que vestem de credibilidade os programas de pós-graduação.

A fragmentação que contagia e, de certa forma, sustenta a pós-graduação, tem como contraponto, na graduação, a sustentação de um conhecimento generalista, marcado por uma racionalidade técnica e instrumental. Conceitos como conhecimento, ci- 
ência, informação e tecnologia não são suficientemente problematizados, mas a racionalidade se mantém amparada pela idéia de finalidade que dirige a formação profissional na graduação. Se a fragmentação do conhecimento privilegia a pós-graduação e a idéia de finalidade configura a graduação, juntas, estas condições reforçam uma separação entre preservação de conhecimento/graduação e geração de conhecimento/pós-graduação.

A pós-graduação tem assegurada a sua autonomia didática e científica, mas ainda não está plenamente institucionalizada. $\mathrm{O}$ suporte financeiro das agências de fomento encoraja a autonomia administrativa e científica, mas, ao mesmo tempo, caracteriza a pós-graduação como um segmento privilegiado na estrutura universitária. Essa condição ambígua continua gerando problemas, atraindo descontentamentos e instaurando desconfiança. Esse tratamento privilegiado coloca, em muitas situações, a pós-graduação em confronto com a graduação, dificultando e até mesmo emperrando diálogos acadêmicos.

A atividade de pesquisa, importante alavanca na geração de conhecimento, e termômetro do desenvolvimento e posicionamento do país frente aos desafios científicos, tecnológicos, culturais e educacionais, é o carro chefe da pós-graduação. Entre os docentes, há um tipo de senso comum sobre a importância da pesquisa na experiência educacional dos alunos. Há, também, a idéia de que a pesquisa deveria integrar o ensino médio e continuar no ensino superior para culminar na pós-graduação. Sabemos, porém, que esta idéia está longe de ser instituída como política institucional.

A ausência dessa política cria dificuldades que se refletem no desequilíbrio e até mesmo na escassez de pesquisas e publicações em determinadas áreas do conhecimento, caso em que a arte serve como exemplo. Há, ainda, divulgação incipiente e irregular das pesquisas realizadas. Podemos dizer que no campo do conhecimento cultural e artístico, as iniciativas que têm logrado continuidade na universidade são fruto da iniciativa, teimosia e tenacidade de alguns docentes pós-graduados que, ao ocuparem função na administração acadêmica e perseguirem um ideal, conseguem mobilizar interesse e apoio para viabilizar tais iniciativas. Assim, fica evidente que na área de arte, a pesquisa ainda luta por espaço institucional. Apesar do status cultural que a arte confere à universidade, a formação para pesquisa, que deveria ter uma forte ênfase na graduação como acontece em outras áreas, ainda é pulverizada e, infelizmente, pouco consistente na área de arte.

Se a formação em pesquisa é incipiente, a atividade de ensino e pesquisa em arte no Brasil, embora crescente, revela inconsistência e irregularidade. $\mathrm{O}$ ensino de arte no ensino fundamental e médio é precário, refletindo a pouca importância que o sistema educacional brasileiro dá à formação cultural, em específico, à arte. Esta precariedade se reflete, também, de várias maneiras, nos cursos de arte no ensino superior. Indefinição em termos de prioridades e certo isolamento em relação ao ensino fundamental e médio, são fatores que contribuem para que os cursos de arte na universidade demonstrem 
dificuldade para sistematizar suas atividades e para fomentar e criticar a produção cultural e artística.

O ensino de graduação, de maneira geral está orientado para respostas. Bom aluno é aquele que sabe responder, de preferência a resposta considerada certa. Uma resposta certa pressupõe informação preservada e acumulada, porém, não necessariamente, a relativização do conteúdo e da pergunta.

O ensino de pós-graduação tem a pretensão de estar orientado para perguntas. Bom aluno é aquele que sabe fazer boas perguntas, de preferência sem arriscar respostas. Uma boa pergunta revela um espírito inquiridor e possivelmente uma predisposição para conviver com a dúvida, porém, não necessariamente, capacidade de argumentação, habilidade para o uso adequado do jargão/terminologia da área ou para discernimento em relação a métodos e procedimentos de investigação.

Aos programas de pós-graduação se deve o mérito de uma fundamentação epistemológica que rompeu com a visão convencional de arte apenas como atividade prática, limitada a uma concepção eruditizante de cultura, e desenvolveram, através da pesquisa, uma concepção de arte como conhecimento. De acordo com essa concepção, ações culturais, artísticas e educacionais se aproximam para se tornarem interdependentes, de modo que as instituições de ensino como meio de produção, difusão e socialização de bens culturais, possam nutrir-se do conhecimento gerado dentro e fora delas, sendo também capazes de promover a crítica desse conhecimento.

A ausência de uma experiência continuada de pesquisa e as contradições que emergem dos monólogos da graduação e da pós-graduação criaram um fosso na institucionalização do conhecimento em arte na universidade. Na graduação, as atividades de ensino parecem apelar mais à memória que à inteligência. Geralmente, alunos com boa memória são premiados ou bem sucedidos.

As atividades de ensino e pesquisa na pós-graduação, considerada a elite acadêmica da universidade, são espaços reservados a docentes com título de doutor ou a professores que, por critérios às vezes tão implícitos quanto complexos, são credenciados como detentores de conhecimento/competência equivalente àquele título. Como membros dessa aristocracia universitária, alguns docentes ostentam superioridade e arrogância em decorrência dos longos anos de dificuldades e estudos estressantes em outro estado, ou, em alguns casos, no exterior, para obtenção de um doutorado. Intitulam-se portadores de um conhecimento sistematizado e se sentem possuidores de um rigor crítico. Quando aturdidos em meio às celeumas acadêmicas, freqüentes no cotidiano da universidade, não hesitam em invocar o título como salvo conduto para justificar e, muitas vezes, impor argumentos, deixando de lado a autocrítica, prática genuína de quem faz pesquisa e produz conhecimento. Ignorando e, muitas vezes, desconhecendo alter- 
nativas para transpor a distância que se espraia entre o conhecimento que ostentam e os problemas que aguardam uma solução de alcance social, esses docentes não promovem esse diálogo tão necessário entre pós-graduação e graduação. Esse tipo de atitude exala odores antigos, ranços de um colonialismo acadêmico que, embora cronologicamente distante, ainda está presente na atmosfera rarefeita da pós-graduação.

A pós-graduação também é vista como uma oligarquia intelectual com um forte potencial para colocar seus docentes em funções de assessoria, coordenação, chefia e direção na estrutura universitária. Essa possibilidade, em princípio desejável por envolver docentes qualificados, tem gerado situações desconfortáveis e contraditórias, visto que 'titulação' per se, não assegura um exercício acadêmico-administrativo competente nas instituições universitárias.

A autonomia didática e científica da pós-graduação não tem sido suficiente para eximi-la de críticas, muita delas também feitas à graduação. Ao discutir as diretrizes e atitudes necessárias à formação do pesquisador, Franchi (1996) expõe algumas dessas críticas:

Muitos programas de pós-graduação escolarizam (no mau sentido) a formação do pesquisador. As atividades se reduzem, muitas vezes, à freqüência a disciplinas oferecidas, sem nenhuma organicidade, por docentes dos mais diversos interesses, tendências e objetos de pesquisa (p. 33).

Ao fazer essas observações o autor põe em perspectiva, de um lado, o "prazer da erudição" e, de outro, o "caráter generalíssimo ou introdutório" dos trabalhos, dissertações e "discussões teóricas". (p. 34) As críticas realizadas por Franchi (1996) põem a descoberto o fato de que a pós-graduação também pode ser dispersiva, carecendo clareza de foco, males frequentemente atribuídos à graduação. Essa crítica aponta para a necessidade de uma prática de pesquisa coletiva, comum em outras áreas de conhecimento, e que pode gerar resultados positivos tanto para a graduação quanto para a pós-graduação. A prática coletiva de pesquisa pode facilitar o diálogo entre pesquisadores, intensificar o interesse e participação de estudantes e otimizar a utilização de recursos.

A atividade dos grupos de pesquisa deve ser vista como prática vital à formação científica/artística, envolvendo docentes, pós-graduandos e graduandos, integrando temas a partir de exercícios empíricos, teóricos e metodológicos. Infelizmente,

A predominância de um estilo individualista de fazer ciência mostrase, ainda, em procedimentos usuais na formação do doutorando [e do mestrando]. Este, em geral, já se vincula ao orientador desde sua admissão ao programa. Em um número excepcional de casos, mas significativo, o individualismo se acentua: a orientação é pratica- 
mente formal e o orientando segue por si, buscando informações, montando a bibliografia através de citações notáveis e não espera do orientador mais que a leitura de seus manuscritos. (FRANCHI, 1996, p. 36)

Paradoxalmente, esse individualismo acadêmico é remanescente histórico de um humanismo que se expressa através de uma erudição livresca em detrimento de uma formação fundamentada na pesquisa. Ele tem raízes no modelo medieval do mestre/ autoridade e ainda encontramos seus resquícios na universidade de hoje.

Liberdade individual e liberdade acadêmica são princípios historicamente associados à idéia de universidade. O exercício desses princípios é, também, um estímulo para que o diálogo, a discussão e a crítica sejam praticados na construção de conhecimento. A liberdade e autonomia conferidas à pós-graduação devem ser extensivas à graduação como condição para que ambas possam cumprir suas funções e reinventar a universidade a partir de ousadias e propostas que ainda não convivem com o cotidiano acadêmico.

\section{Considerações finais}

Se preservar e gerar conhecimento são funções precípuas à universidade, a atividade docente, tanto na pós-graduação quanto na graduação é instigar e cultivar essas práticas. Os seres humanos estabelecem relações de conhecimento e de compreensão do mundo por meio de mediações em que experiências vividas no presente são associadas a elementos de experiências anteriores, no passado, e projetam possibilidades de compreensão e experiências para o futuro. Nessa trama de relações, experiências, percepções e fatos o conhecimento é adquirido a partir da ação intencional que tem repercussões de caráter social e histórico. A necessidade de criar e partilhar significados congrega os seres humanos em torno de experiências e referências comuns ajudando-os a romper com o isolamento e a reforçar a convivência social.

Sendo o conhecimento um produto das relações dos seres humanos com o meio onde vivem e com os sistemas simbólicos, as atividades que investigam, problematizam e historicizam essas relações podem ser descritas como formas de gerar conhecimento. $\mathrm{Na}$ participação e aprendizado dessas relações e atividades, as tentativas de explicar a arte como modalidade de conhecimento devem ter como foco e ponto de partida a cultura e os sistemas simbólicos que constroem seus significados, que alimentam, integram e informam as práticas vigentes, as concepções teóricas e a experiência artística.

Um exame cuidadoso dos aspectos da formação cultural da universidade brasileira revela que a discussão de questões pertinentes como liberdade, autonomia, modelo institucional (graduação e pós-graduação) e individualismo acadêmico são tão antigos 
quanto a universidade ou, em muitos casos, antecedem sua criação. Isto nos faz crer que essas práticas, germes de conflitos e contradições, só poderão ser reinventados se, a partir de uma compreensão crítica do passado, nos dispusermos a operar essas transformações no presente. Conforme explica Goodman (1995),

Os sistemas de símbolos através dos quais as versões de mundos são construídas são de inúmeras espécies, tais como (...) as teorias científicas e filosóficas, as pinturas, os poemas, as composições musicais e as outras artes. Nenhuma versão tem qualquer espécie de prioridade que justifique a redução de todas as outras (p. 9).

Ao fazer essas considerações proponho que uma epistemologia da arte contemple tanto a modalidade de conhecimento não-proposicional quanto a proposicional, abrangendo categorias que, do ponto de vista epistemológico, atendam as diferentes formas de experiência e aprendizado cultural e artístico. A formação de pesquisa oferecida nas instituições de ensino superior compreende esses postulados como a sustentação epistemológica da área. Os diferentes tipos de informação - sensorial, perceptiva, técnica, metodológica, conceitual/histórica, cultural, etc. - legitimam a função que os identifica como matéria-prima indispensável ao processo de construção de conhecimento em arte. A organização, sistematização e circulação da informação nas áreas de conhecimento são indicadores que revelam o aprofundamento, o estado da pesquisa e, principalmente, o amadurecimento da área.

A dicotomia corpo/mente pode ser vista como diagnóstico que revela sintomas da área. Sendo uma referência significativa, funciona como termômetro para indicar a temperatura e para avaliar o estado da pesquisa em arte. Feito o diagnóstico e tirada a temperatura, nos resta estreitar as relações entre pesquisa, ensino e prática artística, mapeando as relações da prática docente com os fundamentos da área: estes são os cacos do nosso ofício.

\section{Referências bibliográficas}

FRANCHI, Carlos. A formação do pesquisador na área de humanidades na universidade brasileira. In: ALBANO, Eleonora; POSSENTI, Sírio; ALKMIN, Tânia (Orgs). Saudades da Língua. São Paulo: Mercado de Letras, 2004, p. 12-38.

JANCSO, István (Org.) Universidade, pesquisa, humanidades. São Paulo, IFLCH/USP, p. 25-46, 1996.

GOODMAN, N. Modos de Fazer Mundos. Porto: Edições Asa, 1995. RYLE, G. The Concept of Mind. New York: Peregrine Books, 1963. 